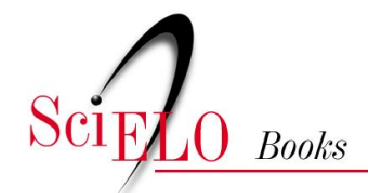

\title{
I - Encontro dos Bispos do Nordeste
}

IV - Planejamento e investimentos

\author{
Dom Jaime Vieira Rocha
}

\section{SciELO Books / SciELO Livros / SciELO Libros}

ROCHA, D. J. V., org. Planejamento e investimentos. In: Sob os signos da Esperança e da responsabilidade social: anais do I e II Encontros dos Bispos do Nordeste (Campina Grande, $1956 \mid$ Natal, 1959) [online]. Campina Grande: EDUEPB, 2016, pp. 161-176. ISBN: 978-85-7879-485-9. Available from: doi: $10.7476 / 9788578794859.0006$. Also available in ePUB from: http://books.scielo.org/id/c6ykx/epub/rocha-9788578794859.epub.

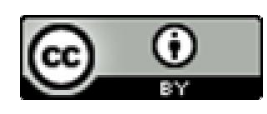

All the contents of this work, except where otherwise noted, is licensed under a Creative Commons Attribution $\underline{4.0 \text { International license. }}$

Todo o conteúdo deste trabalho, exceto quando houver ressalva, é publicado sob a licença Creative Commons Atribição 4.0.

Todo el contenido de esta obra, excepto donde se indique lo contrario, está bajo licencia de la licencia Creative Commons Reconocimento 4.0. 


\section{IV - Planejamento e Investimentos}

Sugestões do $1^{\circ}$ Grupo de Estudos do I Encontro dos Bispos do Nordeste, coordenado pelo Relator Rômulo Almeida (Plano a longo prazo).

Os esforços nacionais em benefício do Nordeste têm parecido da mesma carência de planejamento que se generaliza a todo o país. Não só é evidente a falta de qualquer programa global, como de projetos específicos adequadamente estudados ou planejados. Esta reunião é um documento da tomada de consciência do NE em relação a essa carência e da atitude regional de liderança no sentido da adoção de um novo método de programação e de investimentos públicos.

Hoje o NE já não se acotovela à caça de pequenos auxílios distritais ou específicos, com que se tentava atacar os efeitos sem tocar nas causas, e reclama um exame e um tratamento global ou estrutural dos problemas da região.

A falta de planejamento se expressa na própria pobreza de documentação ou de informações básicas, sem as quais ele não se pode realizar, e nem mesmo florescer qualquer surto de investimentos espontâneos ou apenas coordenados por uma consciência comum dos fatos e pela formação sedimentar de uma política comum.

Há um folclore generalizado de que "no Brasil se planeja demais, o que falta é execução"; pelo contrário, a experiência do NE revela uma sucessão anárquica de ideias imaturas e projetos apressados, quando não de simples formulações, em termos convencionais, de interesses políticos ou econômicos de pequenos grupos ou pessoas, os quais têm sido rotulados como planos, programas ou projetos.

Entre eles devemos ressaltar projetos respeitavelmente elaborados sob o ângulo de engenharia, porém incompletos, por exemplo, quanto à avaliação de custos e benefícios. 
Em consequência, verifica-se a execução simultânea e interminável de uma infinidade de coisas, desarticuladas entre si, resultando em altos custos e baixa produtividade dos investimentos feitos tanto pelo governo federal, como pelos estaduais.

Grandes desperdícios têm sido assim verificados, na experiência tradicional, pela falta de planejamento adequado, seja o individual dos projetos ou empreendimentos isolados, seja o conjunto, que realize a coordenação global dos diferentes projetos.

Os órgãos técnicos, pela sua subordinação natural, bem como pela falta de pessoal qualificado em número suficiente, estão indefesos face às injunções políticas na elaboração dos orçamentos e dos programas de obras; e, por sua vez, os políticos refletem, de um lado a insuficiência de informações pela imaturidade dos estudos sobre os projetos específicos e a posição destes no conjunto, e, de outro lado, pela incipiência de formação da opinião pública quanto às prioridades e outros critérios de planejamento para o desenvolvimento regional.

O planejamento se impõe, dessa forma, para a mobilização e conjugação de todos os esforços no sentido do desenvolvimento do NE e, paralela e consequentemente, da redução dos efeitos das secas sobre sua economia.

O planejamento de um grande programa nacional para o NE, auxiliando a iniciativa pública e privada regional, se justifica, ainda, pelo conjunto de recursos naturais e humanos de que dispõe a região e possibilitam o florescimento de uma economia em que se eliminem os baixos padrões de vida do nordestino comum e se permita uma substancial contribuição do NE para a expansão da economia nacional.

\section{Mudança de métodos e carência de técnicos}

Cabe, porém, advertir, que planejamento implica numa mudança de mentalidade, de atitudes, de métodos de trabalho. Aplicar o nome de planejamento ao açodamento na elaboração de listas de aquisições ou obras é simplesmente desmoralizar o vocábulo: é usar uma palavra fugindo ao seu adequado conceito.

Planejamento implica numa documentação preliminar e em pesquisas responsáveis que dêem uma consciência dos recursos efetivos 
ou fatores de produção e uma consciência de interdependência e de sucessão dos vários programas e projetos, orientem quanto ao estabelecimento consequente de prioridades (face à limitação dos recursos), e adicionalmente se expressa ainda na análise das relações custos - benefícios e na seleção entre diferentes alternativas na solução dos problemas ou na projetação dos empreendimentos.

A partir dos esforços preliminares de coordenação ou planejamento, de que resultou o próprio Banco do Nordeste do Brasil, já dispõe, hoje, a região de uma organização técnica de documentação e estudos - o ETENE - que, de sua parte, vem preparando, com a colaboração de outros órgãos, como a CAPES e a Universidade da Bahia, uma equipe de especialistas. Mas ainda ressalta a grande escassez de técnicos para os próprios trabalhos de planejamento, bem como para a execução dos programas e empreendimentos planejados.

Donde a importância da formação de pessoal, a qual deve constituir o primeiro (embora simultâneo a outros) dos investimentos para o desenvolvimento regional.

As dotações despendidas pelo Governo Federal nas universidades seriam mais que suficientes, se não fossem, como são, aplicadas sem a preocupação oportuna de produtividade social, num sistema educacional que não prepara nem os especialistas, nem os generalistas e humanistas no número e nas condições requeridas pelo processo de desenvolvimento.

O agudo problema de pessoal e a pobreza das pesquisas ressaltam a importância da assistência técnica, pelos órgãos federais ou de Estados mais experimentados em certos campos, bem como das entidades internacionais, uma vez adequadamente ajustadas às condições da região.

\section{Grupo de Planejamento do Nordeste}

Indispensável é também que o novel Conselho de Desenvolvimento Econômico, criado pelo Exmo. Sr. Presidente da República, não absorva os recursos técnicos à sua disposição apenas no estudo dos grandes empreendimentos na escala nacional, ou solicitados pelo sul do país, mas os disponha também, compreensivamente, para a tarefa do planejamento regional, especialmente do Nordeste. Convém advertir que se se retardar 
o trato dos problemas desta região, há muita probabilidade - e risco - de que o plano de desenvolvimento regional do país, em outras palavras, uma distância maior entre o Sul e o Nordeste e Norte do país.

É auspicioso, entretanto, registrar o ato do Exmo. Sr. Presidente da República criando, no Conselho de Desenvolvimento, o Grupo de Planejamento do Nordeste.

\section{Investimentos}

Maiores investimentos dependem de capital formado na região e aqui fixado, ou atraído de fora. Para isto se acentua a necessidade de bom planejamento global, bem como de bons projetos.

O primeiro alvo é mesmo alcançar maior produtividade, pela adoção de um método de planejamento, dos investimentos que já são feitos na região, sejam os particulares, cuja produtividade não é maior à falta de condições básicas de "capital social", sejam os investimentos públicos, destinados em princípio à criação destas condições básicas, mas que em grande parte se esterilizam hoje na pulverização das dotações, na descontinuidade, na pressa dos projetos mal estudados e na ausência de coordenação.

Não basta dispor do capital financeiro, importam sobretudo os recursos efetivos, ou sejam, os físicos e os humanos.

É preciso, ainda, afastar a noção errônea do que a simples existência de recursos físicos permite uma produção, "se houver dinheiro". Necessário é que exista a figura do empreendedor, ou seja, do líder do empreendimento, tanto no investimento privado quanto no público; e que esse condutor ou possa por si, nos casos mais simples, em que há uma experiência consagrada, traçar bom projeto, ou possa mobilizar os técnicos necessários para este fim.

O projeto verificará se há mercado - condição essencial (no caso de investimentos públicos não recuperáveis, se há utilização que o justifique em preterição de outros), e se as condições de custo são as melhores que possam ser obtidas, de sorte que a relação benefícios - custos seja a mais elevada.

É preciso contar também com o tempo de maturação dos investimentos, em cada caso especifico, bem como com o tempo de maturação 
de um investimento global, que é um plano ou programa regional. "Roma não se fez em um dia".

Pareceram ao grupo dignos de aprovação os critérios sugeridos pelo BNB para o tratamento prioritário dos projetos:

$\left.1^{\circ}\right)$ que proporcionem mais emprego por unidade de capital, que é fator escasso;

$\left.2^{\circ}\right)$ que contribuam com um maior valor adicionado por unidade de capital; o valor adicionado é a soma dos salários e ordenados, juros, alugueis e lucros, e representa a verdadeira contribuição de um projeto para o aumento da renda de uma comunidade;

$3^{\circ}$ ) que economizem ou criem divisas (substituição de importações ou aumentos de exportações);

$\left.4^{\circ}\right)$ que promovam ou criem incentivos ao aparecimento ou expansão de indústrias;

$\left.5^{\circ}\right)$ que promovam ou criem incentivos ao aparecimento ou expansão das atividades agropecuárias;

$\left.6^{\circ}\right)$ que sejam dotados de estabilidade, isto é, não sujeitos a flutuações; ou contribuam para reduzir a instabilidade da economia regional;

$\left.7^{\circ}\right)$ que atendam ao requisito da essencialidade, quanto à rigidez da demanda ou as necessidades elementares da população.

\section{Considerações gerais para ampliar os Investimentos no Nordeste}

Além da existência de bons projetos e programas, sem falar num plano integrado, a experiência mostra que há condições gerais que podem ser objeto de medidas imediatas, conquanto em alguns casos ou implicações dependam de estudos mais acurados.

\section{Politica Monetária Regional}

Não se tem dado importância a uma das contribuições mais importantes para elevar de pronto a produtividade da economia regional: o 
estabelecimento de uma política financeira adequada - a ser não apenas adotada pelos Estados mas especialmente aceita e seguida pelos órgãos da política monetária da União. Assim é indispensável regionalizar ou federalizar as normas financeiras relativas tanto ao ritmo e aos critérios de pagamentos do orçamento federal, como ao crédito, de sorte que as finanças federais exerçam um papel compensatório nas crises estacionais ou ocasionais da economia regional. Presentemente a sensibilidade é muito remota nas instituições federais para esse problema vital à economia regional.

Em complemento a isso, é indispensável, ainda, considerar certas condições estruturais ou permanentes da economia regional, como seja a natureza dos seus recursos. Assim, é um absurdo estender à região numerosas limitações dos chamados "planos de economia" e de certas restrições de crédito, segundo os mesmo critérios e escalas adotados para o Sul do País. No Nordeste se encontram grandes massas de trabalhadores não qualificados ou de baixa qualificação, em situação de duro desemprego ou se sub-emprego, cuja utilização, portanto, através de um programa público, representa um acréscimo liquido de renda nacional. A demanda derivada, de certos bens escassos provenientes de importações ou de produções nacionais, é ínfima nos casos desses trabalhadores, cujos salários se aplicam nas primeiras necessidades.

Como condenar ou lamentar que aumente a demanda de alimentos essenciais, se estão sub-nutridos? E ainda se tem havido e há possibilidades de ampliar sua produção? Da indústria fabril, sua maior demanda é de tecidos grossos, para que há capacidade excedente de produção no país. Os efeitos inflacionários não são portanto de temer, como em outras regiões de emprego pleno, e tanto mais em face dos imperativos de dar meio de vida a essa gente.

No que se refere à política de crédito, além do seu papel compensatório já referido, deve-se aplicar a mesma indicação anterior sobre os recursos e daí concluir, sem ofender a uma política de combate à inflação, por uma prioridade especial em favor da região, no que toca ao crédito para investimentos pelos bancos nacionais. 


\section{Orçamento Federal}

Um dos primeiros trabalhos deve ser o estudo da proposta de orçamento federal para 1957, bem como do "plano de economia" relativo ao de 1956. No sistema de loteamento do orçamento pelas influencias políticas distritais, à falta de programas partidários e de suficiente disciplina da maioria parlamentar, sabemos que pouco se pode obter no sentido do estabelecimento das prioridades mais convenientes para um maior rendimento da ação governamental, em termos de maior produção. Mas alguma coisa deve ser alcançada por um planejamento convincente e um trabalho de persuasão no Congresso.

\section{Política de Câmbio e Importações}

É indispensável que para essa região se efetivem prioridades especiais no que se refere a:

a) Bonificações melhores para seus produtos de exportação ou investimentos federais compensatórios, pois a região poderia ter muito melhores condições não fora o chamado "confisco cambial";

b) Registro de transferência de capitais reduzindo-se a exigência quanto ao risco de sua cobertura pelo mercado livre;

c) Registro de financiamentos estrangeiros em condições mais favoráveis;

d) Licenciamento de importações, especialmente equipamentos e matérias primas, uma vez que efetivamente destinados à utilização na região, com menores exigências;

e) Cotas de cambio para tais importações e para programas públicos considerados prioritários no plano de desenvolvimento regional;

f) Ágio mais favorável para equipamentos destinados a indústria e à agricultura. 


\section{Investimentos Públicos}

No estágio de sub-desenvolvimento da região, os investimentos públicos são decisivos. Dada a pobreza dos Estados e municípios, mais importante é a contribuição da União. Seja através do orçamento para os investimentos de base, irrecuperáveis, seja através dos bancos federais, para os investimentos recuperáveis.

Como objetivo de um planejamento cuidadoso, cabe esperar um programa mais amplo e concentrado de investimentos federais que vença de vez os obstáculos maiores ao desenvolvimento regional, transformando o NE, graças à variedade e importância dos recursos, apesar das secas periódicas, numa região próspera no Brasil.

A situação atual do NE resulta, segundo convicção do grupo, da insuficiência quantitativa e qualitativa dos investimentos que aqui tem sido feitos.

Cabe, a curto prazo, realizar esforços na esfera federal, no sentido de:

a) Revisão do orçamento da União quanto ao NE, para melhor atender aos objetivos básicos de desenvolvimento;

b) Melhor aparelhamento dos órgãos federais responsáveis pelos investimentos públicos ou estimuladores dos particulares, como são exemplos o D.N.O.C.S. e o D.N.P.M., ambos carentes de técnicos;

c. Coordenação entre os órgãos federais na aplicação dos recursos;

d) Maior utilização dos Estados e municípios para a aplicação dos recursos federais, seja tendo em vista os mais baixos custos que tem relativamente ao governo federal, seja tendo em vista radicar na região recursos técnicos e administrativos.

Desde já são indicados auxílios aos Estados para as obras e serviços contra as secas ou seus efeitos.

O sistema de convenio, uma vez bem planejado, e a racionalização do auxílio federal, obedecendo às condições de produtividade, necessidade e esforço próprio, contribuem para o maior rendimento das aplicações federais. 
a) Investimentos federais compensatórios do "confisco cambial" que incide sobre os produtos da região.

\section{Campos Preferenciais e Recursos}

Os campos preferenciais de aplicação são os seguintes, com algumas indicações que parecem desde já justificadas:

Energia - Os pontos fundamentais, no momento, face aos investimentos base existentes ou em curso e às disponibilidades potenciais de eletricidade e petróleo, com Paulo Afonso e Mataripe, são:

a) Acelerar a instalação das redes locais de distribuição de eletricidade, inclusive para irrigação, mas, sobretudo aproveitando as concentrações urbanas existentes e as possibilidades industriais;

b) Executar ou estudar as linhas de transmissão às regiões que comportem, pela sua demanda potencial, a amortização dos investimentos respectivos, com o Cariri e o oeste do R.G.N., neste caso conjugado com o plano industrial da área salineira;

c) Melhorar o sistema de distribuição a granel de combustíveis líquidos no interior, de sorte a baratear-lhes os preços.

\section{Transportes e Comunicações}

a) Atualizar e levar a pronta execução os estudos - aliás muito incompletos - realizados pela CMBEU sobre o reequipamento das ferrovias da região;

b) Não retardar o programa de melhoria dos portos da região;

c) Acelerar o programa nacional da navegação de cabotagem, que é um dos problemas básicos para o Nordeste, amparando outrossim a União os programas locais de navegação, como é o caso da tradicional Companhia de Navegação Bahiana;

d) Investimentos em rodovias de acordo com os objetivos econômicos imediatos e com a conveniência da coordenação com os outros meios de transporte;

e) Elaboração de um plano rodoviário integral sem distinguir as rodovias dos vários "planos" atuais ou seja, sem distinguir 
"federal" da "estadual" ou da "municipal", mas tendo em mira o estabelecimento de prioridade com base econômica e a coordenação de meios dos três poderes;

f) A revisão dos programas de construções ferroviárias, abandonando-se as ligações supostamente estratégicas que representam um fator de empobrecimento do país, e assim de perda do potencial de defesa, pelos programas ferroviários de pronto interesse para a economia da região;

g) Reequipamento do D.C.T. na região que vive praticamente isolada;

h. Ajuda federal através de prioridade na política financeira e cambial para as instalações telefônicas na região, em grave insuficiência, bem como de crédito.

\section{Solo e Água}

Os investimentos neste setor têm evidente prioridade na região, mas devem levar em conta a maturidade técnica dos projetos e seu rendimento sob a forma de terra irrigável, regularização de correntes; energia; acumulação mais barata de água para as épocas de seca; maior contribuição para a saúde pública, maior utilização industrial.

Devem ser considerados prioritariamente o aproveitamento das correntes permanentes, como o São Francisco e outros rios da região, os vales úmidos existentes em vários Estados da região e as bacias irrigáveis de aludes já construídos.

Deve ser prevista a compra e desapropriação da terra necessária para que os investimentos públicos beneficiem a um maior número. Neste sentido, o Congresso deve ser solicitado a votar uma legislação, há tempos proposta, mais compatível com a utilização social da terra, inclusive, se necessário, através de reforma constitucional.

Neste campo, cumpre indicar, especificadamente, um investimento que, embora não localizado na região, terá efeitos de extraordinário alcance para as fontes de energia e de vida da região, através da regularização do rio São Francisco, aumento do seu volume na estação seca e quase duplicação da capacidade de Paulo Afonso - trata-se da barragem das Três Marias, no alto São Francisco, em território mineiro. 


\section{Pesquisa, Educação, Assistência Técnica e Saneamento}

Além desses campos, o Grupo considera importante a expansão, em base mais eficientes, dos programas de pesquisas (mineral, agronômica, pesca, social, econômica, etc.), educação, assistência técnica (inclusive fomento agrícola) e saneamento.

\section{Medidas para provocar Investimentos Particulares}

São investimentos intangíveis em geral, porém, indispensáveis para o processo do desenvolvimento econômico e social. A propósito de educação, aliás, vale notar que a educação humanística efetiva, realista e não livresca, ao lado de formação técnica, é uma fonte para o florescimento das ideias, o desenvolvimento da capacidade de direção e do espirito de iniciativa.

Além das condições gerais, que dependem de investimentos públicos no "capital social" da região, podem ser tomadas medidas, desde já, no sentido de desenvolver as informações sobre possibilidades regionais (o que, entretanto, depende, a partir de certo limite, de melhores pesquisas sobre os mercados e os recursos regionais), bem como quanto à cooperação de esforços financeiros, através de cooperativas ou sociedade anônimas, de sorte a possibilitar a captação e acumulação de pequenos recursos esparsos.

Esse esforço tanto deve ser de entidade púbicas como particulares e se pode racionalizar através da criação de sociedades de investimentos, uma vez que com alta e indiscutível idoneidade.

O papel do BNB será muito importante nessa provocação de novos investimentos. Deve ser registrado com satisfação o programa de preparação de pessoal habitado que está executando para esse fim.

\section{Recursos do Nordeste e Oportunidades de Investimento}

O grupo considera como base de sua convicção de que NE é, em conjunto, um bom investimento, que cumpre planejar a grande variedade e riquezas dos recursos de que dispõe. 
O fator humano, embora carente de formação cientifica e técnica tem mostrado grande vigor mental, capacidade de trabalho e adaptação à disciplina e às exigências técnicas de grandes empreendimentos, como são os casos de Paulo Afonso e do parque petrolífero do Recôncavo. A própria Campina Grande, com grande número de suas oficinas e pequenas fábricas, é um exemplo da capacidade do povo nordestino, para o que em quase nada concorreu o sistema educacional.

Os recursos naturais apontam diversas linhas de investimentos particulares, bem como semi-públicos, ou públicos, para cujos produtos há possibilidades evidentes de mercados no país ou no estrangeiro.

\section{Recursos Agrícolas}

Frequentemente a opinião pública se desapercebe de que o NE não se limita à área sujeita às secas. Tem, pelo contrário, importantes zonas de umidade permanente ou equivalente à das zonas agrícolas do sul.

$\mathrm{Na}$ área sujeita às secas, porém, a frequência de anos chovidos é maior do que a de anos flagelados pelas secas. A estatística mostra que nelas se produz o grosso da produção alimentar da região, excetuadas as culturas comerciais de cana de açúcar e do cacau. Um melhor aproveitamento permitirá melhor aproveitamento da vocação do Polígono para produzir cereais e outros gêneros.

Suas possibilidades agrícolas estão ainda longe de total aproveitamento, através de plantas já adaptadas, como algodão, sisal e palma, e outras que podem ser introduzidas. Certo é que, baseado na própria área seca, o NE é normalmente auto-suficiente quanto aos alimentos básicos que consome e grande exportador de diversas e valiosas matérias primas de origem vegetal e animal.

Em síntese: a própria zona seca não é desanimadora quanto a seus recursos agrícolas.

Adicionalmente, porém, o NE apresenta, para melhor aproveitamento, as margens dos rios permanentes, os vales úmidos, as bacias irrigáveis de açudes já construídos, os tabuleiros, além de zonas úmidas extensas, mal utilizadas ou não exploradas, ao longo da costa, em vários Estados, sobretudo, nos extremos da região, ou seja, no baixo Parnaíba e no Maranhão e no sul da Bahia, onde as possibilidades para produção 
de alimentos vegetais e animais, e matérias primas, inclusive madeiras, são ainda muito amplas. A insuficiência de estudos é informações sobre mercados e de preparação para eles, bem como de assistência técnica e crédito, mas ajustadas a essas outras condições, é que tem determinado um retardamento no ritmo de desenvolvimento agrícola do NE.

Cumpre, desde já, promover ou incentivar (com auxílios adequados da União) as inversões destinadas:

a. À organização da economia agrícola, com as redes de armazéns e silos, organizados em forma responsável.

b. Ao melhor aproveitamento das matérias primas agrícolas, especialmente os produtos alimentares (matadouros, usinas de beneficiamento, indústrias alimentares etc.).

c. À produção e suprimento de materiais e equipamentos agrícolas, como adubos, forragem, inseticidas, vacinas, máquinas agrícolas, equipamentos de irrigação.

Dada a insuficiência de recursos técnicos e de capitais na região, o papel do Ministério da Agricultura é muito mais importante para o Nordeste e todo o Norte, que para o Sul. Recomenda-se, porém, que ele atue de preferência em colaboração com os governos locais e entidades privadas, de que é exemplo destacado a ANCAR.

\section{Pesca}

Deve ser referida a importância especial da pesca, pelas suas possibilidades, já comprovadas na região, bem como pela maior carência de proteínas na alimentação e, ainda, por se tratar de uma atividade econômica em que há indicações de serem mais favoráveis as relações benefícios-custos e produto-capital.

\section{Recursos Minerais e Indústrias Metalúrgicas e Químicas}

Os variados recursos minerais do NE, em regra descobertos por acaso, são importantes no programa de tornar a região menos dependente das secas. Foi referido que, em todo o NE, só há trabalho de 
campo, 2 (dois) técnicos do DNPM, sediados no Laboratório de Campina Grande, indicando-se, portanto, com urgência, a ampliação dos programas de pesquisas minerais em toda a região, onde certas indicações fazer crer que o Brasil se poderá suprir dos escassos "não-ferrosos".

Além das descobertas de minérios de urânio e tório na região, foram referidas, a título de indicações concretas, de possibilidades industriais, entre outras, na base de recursos do reino mineral, as seguintes:

a) Desenvolvimento da produção de fosfatos em Olinda;

b) Produção de soda eletrolítica associada à produção dos fosfatos em Pernambuco;

c) Indústria de soda baseada nas salinas do Rio Grande do Norte, segundo o processo clássico, podendo ainda o parque salineiro de Macau-Areia Branca, comportar uma variedade de outros produtos como bromo e potássio;

d) Indústria de soda cáustica baseada nas jazidas de salgema de Sergipe;

e) Metalurgia da chelita;

f) Orientação deliberada para a Bahia de parte da indústria petro-química que se projeta montar no país, com o apoio da Petrobrás e do Governo, como negro de fumo, poliestireno e benzol, parafina, nitrogênio, etc.;

g) Metalurgia do cobre, baseada nas jazidas de Caraía, ferro-manganês, cromo e chumbo;

h) Indústria de alumínio no ponto mais adequado baseado na energia de Paulo Afonso e, enquanto não se descobrirem jazidas regionais de bauxita, com importação dessa matéria prima ou da alumina do sul do país ou mesmo do estrangeiro (neste caso, mesmo com pagamento por meio do próprio alumínio metálico exportado);

i) Usina siderúrgica no ponto mais indicado para produzir ao menos os vergalhões necessários ao mercado regional e, no futuro, usina maior com o minério do São Francisco;

j) Refratários de magnesita e diversas outras matérias primas irmãs. 


\section{Indústria De Consumo}

No que se refere à indústria de consumo, cabe pleitear certa liberalidade para os critérios referentes a novos investimentos e importações do NE.

Assim, é de fundamental importância que o acréscimo do mercado nacional de tecidos seja atribuído ao Nordeste, através das possibilidades de câmbio, importações e investimentos em cruzeiros. O Nordeste produz excelente algodão, tendo o privilegio das fibras longas. Entretanto, a região tem um déficit no comércio de tecidos. Suas fábricas, porém, estão encontrando dificuldades para importação de equipamentos, mesmo através de "créditos" ou de "transferência de capitais", pelo fato de que a indústria nacional de tecidos, localizada no centro e no sul do país, tem, no momento, uma capacidade de produção não plenamente utilizada. Ora, ocorre que o crescimento da demanda nacional é bastante intenso e se manifesta, sobretudo, na maior demanda de tecidos médios e finos, para o que o NE tem condições melhores de matérias primas. Por outro lado, o mercado regional tende a crescer consideravelmente (um alto coeficiente relativamente ao próprio crescimento da população) com o programa de desenvolvimento regional. Portanto, cabe atender aos projetos de desenvolvimento da indústria de tecidos na região, no sentido de criar empregos, reduzir o desequilíbrio comercial interno e, até mesmo, economizar divisas consumidas nos transportes, sobretudo rodoviários, entre o sul do país e o Nordeste. Desta maneira, se indica a adoção de medidas de estimulo para a indústria de fiação e tecelagem de preferência no Rio Grande do Norte, no caso do aproveitamento das fibras longas do Seridó.

No ramo têxtil, deve ser considerada desde já a indústria de produtos do sinal ou agave.

Quanto às indústrias elementares, em que a melhor utilização da produção animal e das matérias primas tropicais ainda encontra largo campo com o mercado assegurado, cabe um lugar importante para o aproveitamento industrial da mandioca, que tem no NE a maior região produtora no Brasil. 
Merece também especial atenção o desenvolvimento das indústrias de materiais de construção, incluindo as de pequeno porte e pequeno alcance territorial. Para a indústria do cimento há grandes possibilidades de expansão, mas as condições presentes são de satisfatório suprimento. Avulta, neste campo, a importância que pode ter na região, uma indústria integrada de madeira, aproveitando as reservas florestais do sul da Bahia e nordeste de Minas, as quais estão sendo devastadas com profundo prejuízo para o futuro do país. Dadas as condições de acesso, riqueza florestal, existência de água, e de alto potencial hidro-elétrico não aproveitado, é possível mesmo pensar-se que isto poderia incluir prontamente uma indústria de celulose e papel, de grande porte, baseada na tecnologia moderna, que permite o uso de madeiras folhudas heterogêneas.

\section{Conclusão}

As indicações de oportunidades que o Grupo pode reunir e apresentar acima, embora possam sugerir medidas oficiais e iniciativas particulares imediatas, não representam um plano, mas apenas uma sugestão a mais para ele. Documentam, sobretudo, quanto "vale a pena" um esforço de planejamento e de investimentos no sentido, de libertar o NE das estranham e desnecessárias dificuldades com que tem lutado. 